\title{
Tissue Factor Detection for Selectively Discriminating Unstable Plaques in an Atherosclerotic Rabbit Model
}

\author{
Takashi Temma ${ }^{1}$, Yuki Ogawa ${ }^{1}$, Yuji Kuge ${ }^{1,2}$, Seigo Ishino ${ }^{1}$, Nozomi Takai ${ }^{1}$, Kantaro Nishigori ${ }^{1}$, Masashi Shiomi ${ }^{3}$, \\ Masahiro Ono ${ }^{1}$, and Hideo Saji ${ }^{1}$ \\ ${ }^{1}$ Department of Patho-Functional Bioanalysis, Graduate School of Pharmaceutical Sciences, Kyoto University, Sakyo-ku, Kyoto, \\ Japan; ${ }^{2}$ Central Institute of Isotope Science, Hokkaido University, Kita-ku, Sapporo, Japan; and ${ }^{3}$ Institute for Experimental Animals, \\ Kobe University Graduate School of Medicine, Chuo-ku, Kobe, Japan
}

Tissue factor (TF), a transmembrane glycoprotein that acts as an essential cofactor to factor VII/VIIa, initiates the exogenous blood coagulation cascade leading to thrombin generation and subsequent thrombus formation in vivo. TF expression is closely related to plaque vulnerability, and high TF expression is shown in macrophage-rich atheromatous lesions, making TF a potential target for detecting atheromatous lesions in vivo. Thus, we prepared $99 \mathrm{mT}$-labeled anti-TF-monoclonal antibody (TF-mAb) IgG as a molecular probe and evaluated its usefulness to achieve TF-specific imaging using myocardial infarction-prone Watanabe heritable hyperlipidemic (WHHLMI) rabbits. Methods: Anti-TF-mAb was created using a standard hybridoma technique and was labeled by $99 \mathrm{mTc}$ with 6-hydrazinonicotinic acid (HYNIC) as a chelating agent to obtain ${ }^{99 m T c-T F-m A b}$. The immunoreactivity of HYNICTF-mAb was estimated by flow cytometry. WHHLMI and control rabbits were injected intravenously with 99mTc-TF-mAb. Twenty-four hours after the injection, the aorta was removed and radioactivity was measured. Autoradiography and histologic studies were performed using serial aorta sections. Subclass matched antibody $\left(\operatorname{lgG}_{1}\right)$ was used as a negative control. Results: HYNIC-TF-mAb showed 93\% immunoreactivity of the anti-TF-mAb. The radioactivity accumulation in WHHLMI aortas was 6.1 -fold higher than that of control rabbits. Autoradiograms showed a heterogeneous distribution of radioactivity in the intima of WHHLMI aortas. Regional radioactivity accumulation was positively correlated with TF expression density $(R=0.64, P<0.0001)$. The highest radioactivity accumulation in percentage injected dose $\times$ body weight $/ \mathrm{mm}^{2} \times 10^{2}$ was found in atheromatous lesions $(5.2 \pm 1.9)$ followed by fibroatheromatous $(2.1 \pm 0.7)$, collagen-rich $(1.8 \pm 0.7)$, and neointimal lesions $(1.8 \pm 0.6)$. In contrast, ${ }^{99 m T c-l g G}$ showed low radioactivity accumulation in WHHLMI aortas that was independent of the histologic grade of lesions. Conclusion: The TF-detecting ability and preferential accumulation in atheromatous lesions of $99 \mathrm{mTc}$-TF-mAb were demonstrated, indicating its potential for selective imaging of macrophage-rich atheromatous lesions in vivo.

Received Jul. 13, 2010; revision accepted Sep. 8, 2010.

For correspondence or reprints contact: Yuji Kuge, Central Institute of Isotope Science, Hokkaido University, Kita 15 Nishi 7, Kita-ku, Sapporo 0608638, Japan.

E-mail: kuge@ric.hokudai.ac.jp

COPYRIGHT @ 2010 by the Society of Nuclear Medicine, Inc.
Key Words: tissue factor; radioimmunodetection; thrombus; atherosclerotic plaque

J Nucl Med 2010; 51:1979-1986

DOI: 10.2967/jnumed.110.081216

$\mathbf{T}$ hrombus formation triggered by plaque rupture is the most important mechanism leading to the onset of acute arterial disease and ischemic sudden death. Thus, the development of a method for detecting thrombus-forming vulnerable plaques before rupture has been clinically desired to more precisely estimate risk and provide effective treatment. Although several molecular imaging probes have been investigated $(1,2)$, the target molecules of such probes were not directly related to the thrombotic process.

Tissue factor (TF), a transmembrane glycoprotein that acts as an essential cofactor to factor (F) VII/VIIa, initiates the exogenous blood coagulation cascade leading to thrombin generation and subsequent thrombus formation. TF expression was identified in atherosclerotic lesions, including in endothelial cells, smooth muscle cells, monocytes, and, especially, macrophages or foam cells (3). In human pathologic lesions, the TF content of de novo lipid-rich plaques was higher than that of stenotic fibrous plaques (4), and such lipid-rich plaque tissue was 6 times more thrombogenic than fibrous plaques. In addition, our recent study also demonstrated that TF expression was closely related to plaque vulnerability, with high TF expression specifically in macrophage-rich atheromatous lesions among heterogeneous atherosclerotic lesions (5). Given these data, $\mathrm{TF}$ is a potential target for probes detecting atheromatous lesions at higher risk for rupture in vivo.

In the present study, we prepared a monoclonal antibody to TF (TF-mAb) and labeled it with ${ }^{99 \mathrm{~m}} \mathrm{Tc}$ ( $\left.{ }^{99 \mathrm{~m}} \mathrm{Tc}-\mathrm{TF}-\mathrm{mAb}\right)$ as a molecular probe. Using an atherosclerosis model (myocardial infarction-prone Watanabe heritable hyperlipidemic [WHHLMI] rabbits) (6), we investigated the accumulation of ${ }^{99 \mathrm{~m}} \mathrm{Tc}-\mathrm{TF}-\mathrm{mAb}$ in atherosclerotic lesions in comparison with histologic characteristics and evaluated the potential of ${ }^{99 \mathrm{~m}} \mathrm{Tc}-\mathrm{TF}-\mathrm{mAb}$ as a molecular probe for detecting vulnerable atheromatous lesions. 


\section{MATERIALS AND METHODS}

Design and Preparation of ${ }^{99 m T c-T F-m A b}$ and ${ }^{99 m}$ Tc-IgG

A monoclonal antibody (mouse $\operatorname{IgG}_{1}$ subclass) for rabbit $\mathrm{TF}$ (193Ser-207Cys, extracellular domain) was established using a standard hybridoma technique. ${ }^{99 \mathrm{~m}} \mathrm{Tc}$-pertechnetate was eluted in saline solution on a daily basis from ${ }^{99} \mathrm{Mo}-{ }^{99} \mathrm{~m}$ Tc generators (Ultra-Techne Kow; FUJIFILM RI Pharma Co., Ltd.).

Anti-TF-mAb was radiolabeled with ${ }^{99 \mathrm{~m}} \mathrm{Tc}\left({ }^{99 \mathrm{~m}} \mathrm{Tc}-\mathrm{TF}-\mathrm{mAb}\right)$ after derivatization with 6-hydrazinonicotinic acid (HYNIC) (7), as previously reported (8). In brief, HYNIC- $N$-hydroxysuccinimide was reacted with $\mathrm{TF}-\mathrm{mAb}$, and the mixture was purified by size-exclusion filtration with a diafiltration membrane (Amicon Ultra 4 [molecular weight cutoff, 30,000]; Millipore Co.). An equal volume of ${ }^{99 \mathrm{~m}} \mathrm{Tc}$-(tricine) $)_{2}$, prepared by the method of Larsen et al. (9), was added to the purified solution of HYNIC-TF-mAb to obtain ${ }^{99 m} \mathrm{Tc}-\mathrm{TF}-\mathrm{mAb}$. After purification by size-exclusion filtration with a PD-10 column, the radiochemical purity of $99 \mathrm{~m} \mathrm{Tc}-\mathrm{TF}-\mathrm{mAb}$ was more than $95 \%$ by another size-exclusion filtration.

For the control study, negative control mouse $\operatorname{IgG}_{1}$ (0102-01; Southern Biotechnology Associates Inc.) was used for the preparation of ${ }^{99} \mathrm{~m} \mathrm{Tc}-\mathrm{IgG}_{1}$. The radiochemical purity of ${ }^{99 \mathrm{~m}} \mathrm{Tc}-\mathrm{IgG}_{1}$ was also estimated to be more than $95 \%$.

\section{Animals}

All animal procedures were approved by the Kyoto University Animal Care Committee. Three male Japanese White rabbits (age, $3 \mathrm{mo}$ ) were used to obtain peritoneal macrophages. For biodistribution studies of ${ }^{99 m}$ Tc-TF-mAb, 5 WHHLMI rabbits (4 male, 1 female; age, 12-18 mo; mean weight $\pm \mathrm{SD}, 3.4 \pm 0.2 \mathrm{~kg}$; supplied by the Institute for Experimental Animals, Kobe University School of Medicine, Japan) were used. Four male Japanese White rabbits (age, 3 mo; mean weight $\pm \mathrm{SD}, 1.9 \pm 0.2 \mathrm{~kg}$ ) were used for the control study. For ${ }^{99}{ }^{\mathrm{m}} \mathrm{Tc}-\mathrm{IgG}_{1}$ studies, 3 WHHLMI rabbits (1 male and 2 female; age, 11-12 mo; mean weight \pm SD, $3.2 \pm$
$0.1 \mathrm{~kg}$ ) were used. The animals were fed standard chow and given water ad libitum.

\section{Immunoreactivity of HYNIC-TF-mAb}

Rabbit peritoneal macrophages were obtained by the method of Ishii et al. (10), with minor modifications. Cells were suspended at a final concentration of $2.5 \times 10^{6}$ cells $/ \mathrm{mL}$ in medium A (Dulbecco's modified Eagle's medium containing $1 \mathrm{mM}$ glutamine, $100 \mathrm{U}$ of penicillin per milliliter, $100 \mathrm{mg}$ of streptomycin per milliliter [pH 7.4], and $0.2 \%$ lactalbumin hydrolysate). Aliquots of the cell suspension were cultured in plastic petri dishes in a humidified $5 \%$ $\mathrm{CO}_{2}$ incubator at $37^{\circ} \mathrm{C}$. After $2 \mathrm{~h}$, each dish was washed twice with $10 \mathrm{~mL}$ of medium A to remove nonadherent cells. Monolayers were cultured for $18 \mathrm{~h}$ at $37^{\circ} \mathrm{C}$ in $20 \mathrm{~mL}$ of medium A, and cells were washed twice with $10 \mathrm{~mL}$ of medium $\mathrm{A}$ and then used for experiments. More than $95 \%$ of the cells were viable, as determined by a trypan blue exclusion test, and almost all of the attached cells showed positive nonspecific esterase staining.

Antibodies $(5 \mu \mathrm{g} / \mathrm{mL}, 100 \mu \mathrm{L}$; TF-mAb, HYNIC-TF-mAb, or negative control $\left.\mathrm{IgG}_{1}\right)$ were added to the cells $\left(10^{6}\right)$ and incubated for $30 \mathrm{~min}$ at $4^{\circ} \mathrm{C}$. After cells were washed, Alexa Fluor 488 goat antimouse IgG antibody (x0931; DakoCytomation) $(10 \mu \mathrm{g} / \mathrm{mL}$, $100 \mu \mathrm{L}$ ) was added for $30 \mathrm{~min}$ at $4^{\circ} \mathrm{C}$. Fluorescence levels were measured using a flow cytometer (Becton Dickinson Inc.). Data were analyzed using BD CellQuest Pro (BD Biosciences), and an immunoreactivity index was calculated as the ratio of the median fluorescence intensity for either TF-mAb or HYNIC-TF-mAb to that of negative-control $\operatorname{IgG}_{1}$. Measurements were performed 3 times per rabbit using 3 Japanese White rabbits, and the ratios were expressed as mean $\pm \mathrm{SD}$.

\section{Biodistribution Studies}

A simple schematic of our experimental protocol is shown in Figure 1 . After $12 \mathrm{~h}$ of fasting, rabbits were initially anesthetized with ketamine (intramuscularly, $35 \mathrm{mg} / \mathrm{kg}$ ) and xylazine (intramuscularly, $5 \mathrm{mg} / \mathrm{kg}$ ). Either ${ }^{99 \mathrm{~m}} \mathrm{Tc}-\mathrm{TF}-\mathrm{mAb}(547-1,024 \mathrm{MBq}$,

FIGURE 1. Simple schematic of this study.

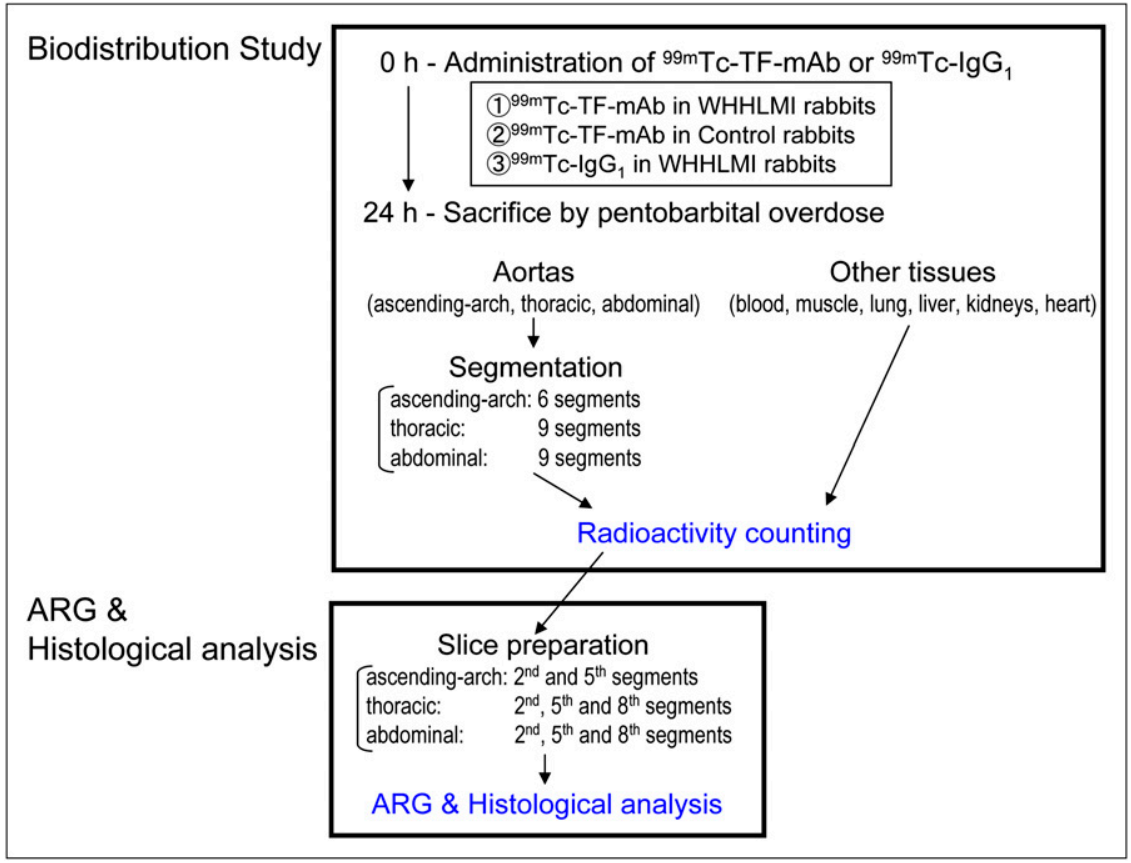
$A R G=$ autoradiography. 
$300 \mu \mathrm{g})$ or ${ }^{99 \mathrm{~m}} \mathrm{Tc}-\mathrm{IgG}_{1}(848-1,038 \mathrm{MBq}, 300 \mu \mathrm{g})$ was injected into a marginal ear vein (5 WHHLMI rabbits and 4 control rabbits for the ${ }^{99 \mathrm{~m} T c-T F-m A b}$ study, 3 WHHLMI rabbits for the ${ }^{99 \mathrm{~m} T c-}$ $\mathrm{IgG}_{1}$ study). Twenty-four hours after the injection, animals were sacrificed by pentobarbital overdose. The ascending-arch, thoracic, and abdominal aortas, blood, and other tissues (muscle, lung, liver, kidneys, and heart) were removed. The ascending-arch aortas were divided into 6 segments, and the thoracic and abdominal aortas were divided into 9 segments. Each segment was weighed and immediately fixed in a solution containing L-(+)-lysine hydrochloride $(75 \mathrm{mM})$ and $4 \%$ paraformaldehyde in phosphate buffer (37.5 mM, pH 7.4) (11). The radioactivity of each sample was measured with a well-type $\gamma$-counter (1480 Wizard 3"; PerkinElmer Japan Co.). The results were expressed as the differential uptake ratio (DUR), calculated as (tissue activity/tissue weight)/(injected radiotracer activity/animal body weight), with activities given in becquerels and weights in grams. The aorta-to-blood (A/B) ratio and the aorta-to-muscle $(\mathrm{A} / \mathrm{M})$ ratio were calculated from the DUR for each tissue sample.

\section{Autoradiography}

Eight segments, the second and fifth segments of the ascending aortic arch and the second, fifth, and eighth segments from the thoracic and the abdominal aortas, from each animal were used for autoradiography studies. These segments were frozen and cut into $20-\mu m$-thick slices with a cryomicrotome. The sections were thawed and mounted on silane-coated slides, which were then placed on a phosphor image plate (Fuji Imaging Plate BAS-MS; Fuji Photo Film) for $24 \mathrm{~h}$ together with a calibrated standard $\left({ }^{99} \mathrm{TcO}_{4}{ }^{-}\right.$solution). The autoradiography images were analyzed with a computerized imaging analysis system (Bio Imaging Analyzer BAS2500 and Image Gauge Software; Fuji Photo Film). The radioactivity in each region of interest was expressed as percentage injected dose $\times$ body weight $/ \mathrm{mm}^{2}$, calculated as (radioactivity in the region of interest)/(injected radioactivity/animal body weight).

\section{Histologic Analysis}

The tissue sections used for autoradiography studies were also subjected to Azan-Mallory and hematoxylin and eosin staining.
Serial sections of the slices from the autoradiography studies were subjected to immunohistochemical staining (for TF, macrophages, and smooth muscle cells) using specific antibodies and an Envision + kit (Dako) with hematoxylin counterstaining. The antibodies used were TF-mAb (4510; American Diagnostica Inc.), rabbit macrophage-specific mAb RAM-11 (Dako), and human smooth-muscle actin-specific mAb 1A4 (Dako). Immunostaining with subclass-matched irrelevant $\mathrm{IgG}$ served as a negative control. Azan-Mallory and hematoxylin and eosin staining were performed by standard procedures. TF expression density was determined as a percentage of the positively stained region using a VHX digital microscope (Keyence Corp.).

\section{Classification of Atherosclerotic Lesions}

We divided atherosclerotic lesions in WHHLMI rabbits into the following 4 categories, using a classification scheme based on the recommendations of the American Heart Association $(12,13)$ and Azan-Mallory and hematoxylin and eosin staining, as previously described (14-17): neointimal (types I-III), atheromatous (type $\mathrm{IV}$ ), fibroatheromatous (types $\mathrm{Va}$ and $\mathrm{Vb}$ ), and collagen-rich (type $\mathrm{Vc}$ ). Supplemental Figures 1A-1P (supplemental materials are available online only at http://jnm.snmjournals.org) show representative photomicrographs of the histologic features of each atherosclerotic lesion category in WHHLMI rabbits.

Regions of interest were placed to cover each atherosclerotic lesion in the aortic section of the WHHLMI rabbit and then transferred to the corresponding autoradiography images (Supplemental Figs. 1Q-1S).

\section{Vulnerability Index}

An index of morphologic destabilization characteristics, the vulnerability index, was calculated for each lesion in the WHHLMI rabbits by the method of Shiomi et al. (18). The vulnerability index was defined as the ratio of the lipid component area (macrophages and extracellular lipid deposits) to the fibromuscular component area (smooth muscle cells and collagen fibers). Collagen fibers and extracellular lipid deposits (extracellular vacuoles and lacunae) were determined with Azan-Mallory stain-

\section{TABLE 1}

Accumulation Levels of ${ }^{99 m T c-T F-m A b}$ and ${ }^{99 m T c-l g G}$ in Aortic Segments of Control and WHHLMI Rabbits at 24 Hours After Injection

\begin{tabular}{|c|c|c|c|}
\hline \multirow[b]{2}{*}{ Segments } & \multicolumn{2}{|c|}{ 99mTc-TF-mAb } & \multirow[b]{2}{*}{${ }^{99 m} \mathrm{Tc}-\mathrm{Ig} \mathrm{G}_{1}, \mathrm{WHHLMI}$} \\
\hline & Control & WHHLMI & \\
\hline Ascending arch & $0.60 \pm 0.05$ & $3.08 \pm 0.57^{\star \dagger}$ & $2.05 \pm 0.42^{*}$ \\
\hline Thoracic & $0.51 \pm 0.11$ & $3.07 \pm 1.44^{\star \ddagger}$ & $1.60 \pm 0.44^{*}$ \\
\hline Abdominal & $0.35 \pm 0.06$ & $2.49 \pm 0.64^{\star \ddagger}$ & $0.76 \pm 0.16^{\star}$ \\
\hline Total & $0.47 \pm 0.04$ & $2.86 \pm 0.85^{\star \ddagger}$ & $1.40 \pm 0.24^{\star}$ \\
\hline Blood & $4.0 \pm 0.6$ & $7.5 \pm 0.0^{*}$ & $7.1 \pm 0.7 \S$ \\
\hline Femoral muscle & $0.6 \pm 0.5$ & $0.3 \pm 0.2$ & $0.4 \pm 0.1$ \\
\hline Aorta-to-blood ratio & $0.12 \pm 0.02$ & $0.38 \pm 0.09 * \ddagger$ & $0.20 \pm 0.02^{*}$ \\
\hline Aorta-to-muscle ratio & $1.0 \pm 0.6$ & $19.3 \pm 19.1^{\star \ddagger}$ & $4.0 \pm 0.4^{*}$ \\
\hline \multicolumn{4}{|c|}{$\begin{array}{l}{ }^{\star} P<0.0001 \text { vs. control rabbits in }{ }^{99 m T c-T F-m A b} \text { study. } \\
{ }^{\dagger} P<0.001 \text { vs. WHHLMI rabbits in }{ }^{99 m} \mathrm{Tc}-\mathrm{IgG}_{1} \text { study. } \\
{ }^{\ddagger} P<0.0001 \text { vs. WHHLMI rabbits in }{ }^{99 m T c-l g G} \text { study. } \\
{ }^{\S} P<0.001 \text {, vs. control rabbits in }{ }^{99 m} \mathrm{Tc}-\mathrm{TF}-\mathrm{mAb} \text { study. } \\
\text { Data are represented as mean } \pm \mathrm{SD} \text { of DUR. }\end{array}$} \\
\hline
\end{tabular}




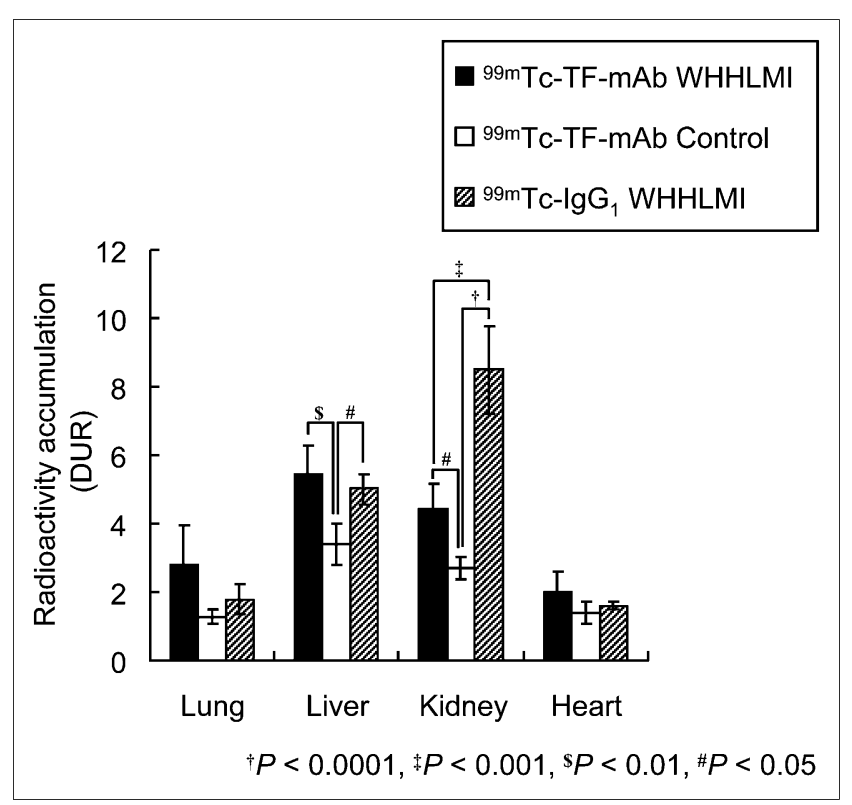

FIGURE 2. Radioactivity distribution in lung, liver, kidneys, and heart. Data are mean $\pm \mathrm{SD} .{ }^{\dagger} P<0.0001$. ${ }^{\ddagger} P<0.001$. ${ }^{\$} P<0.01$. ${ }^{\#} P<0.05$.

ing. Macrophages and smooth muscle cells were determined with immunohistochemical staining (17).

\section{Statistical Analysis}

Data are presented as mean \pm SD. Statistical analysis was performed with the Mann-Whitney $U$ test to compare aortic segments of WHHLMI and control rabbits (Table 1). Radioactivity that accumulated in nontargeted organs among antibodies and animals was compared using 1-way ANOVA, with post hoc analysis by the Holm test (Fig. 2). Correlation coefficients were assessed by Spearman rank correlation coefficients (Fig. 3). Lesion types were compared using the Kruskal-Wallis test, with post hoc analysis by the Scheffé test (Fig. 4). A 2-tailed value of $P$ less than 0.05 was considered statistically significant.

\section{RESULTS}

\section{Immunoreactivity of HYNIC-TF-mAb}

Using fluorescent-activated cell sorter analysis of rabbit peritoneal macrophages, we could clearly distinguish the signals of TF-mAb and HYNIC-TF-mAb from that of the negative control $\mathrm{IgG}_{1}$. The median fluorescence intensity ratios of TF-mAb and HYNIC-TF-mAb to control $\mathrm{IgG}_{1}$ were $2.90 \pm 0.06$ and $2.69 \pm 0.11$, respectively, and the difference between the labeled and unlabeled TF antibodies was not statistically significant.

\section{Biodistribution Studies}

Accumulation levels of ${ }^{99 m} \mathrm{Tc}-\mathrm{TF}-\mathrm{mAb}$ and ${ }^{99 \mathrm{~m}} \mathrm{Tc}-\mathrm{IgG}_{1}$ in the aortic segments of WHHLMI and control rabbits are summarized in Table 1. The accumulation level of ${ }^{99 \mathrm{~m}} \mathrm{Tc}-$ TF-mAb in each aortic segment of WHHLMI rabbits (ascending arch, $3.08 \pm 0.57$ DUR; thoracic, $3.07 \pm 1.44$ DUR; and abdominal, $2.49 \pm 0.64$ DUR) was 5.1- to 7.1fold higher than that of control rabbits (ascending arch,
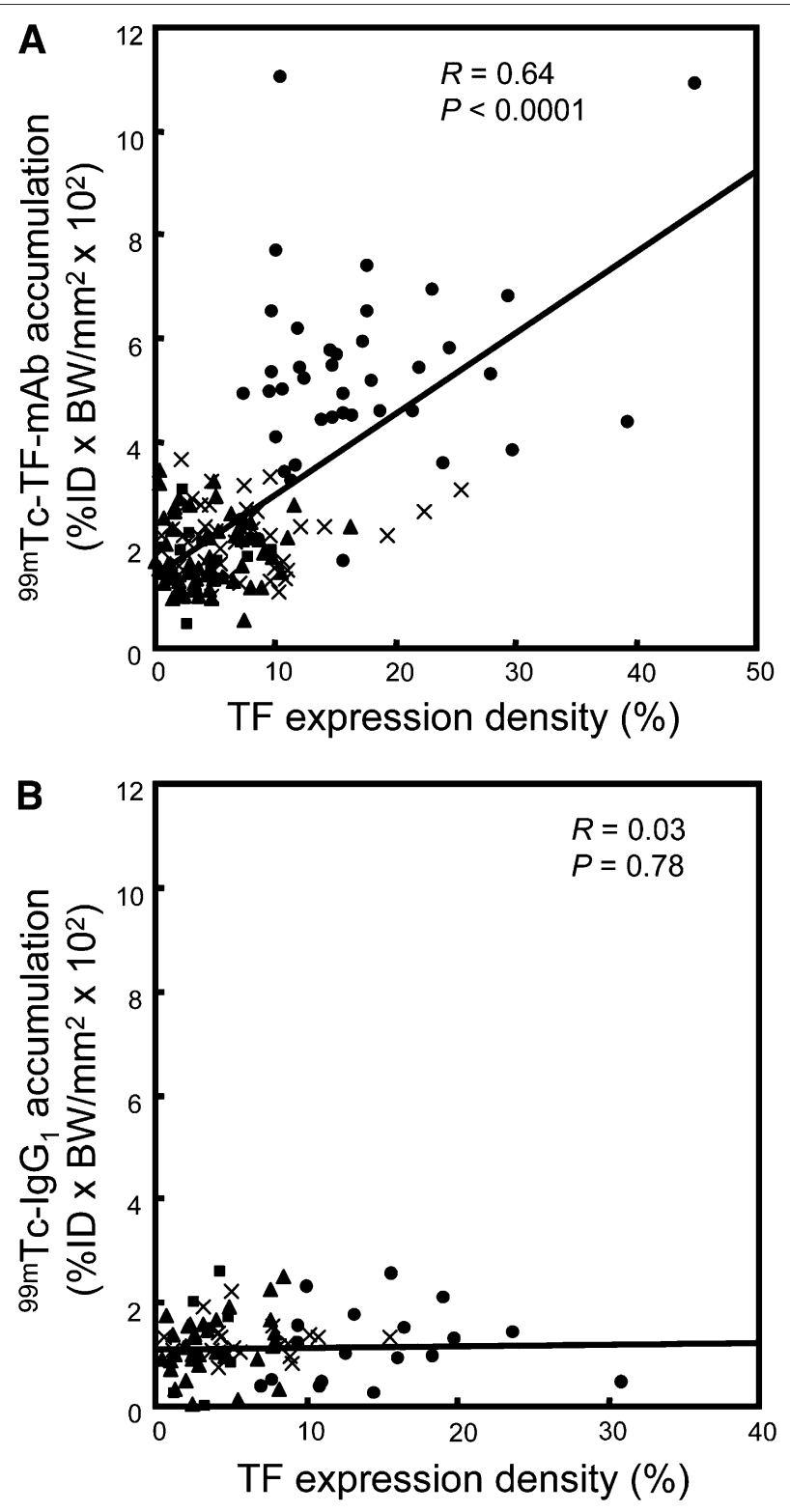

FIGURE 3. Regression analyses of TF expression density with ${ }^{99 m} \mathrm{Tc}-\mathrm{TF}-\mathrm{mAb}(\mathrm{A})$ and ${ }^{99 m} \mathrm{Tc}-\mathrm{IgG}_{1}(\mathrm{~B})$ accumulation. = neointimal lesion; $\bullet=$ atheromatous lesion; $x=$ fibroatheromatous lesion; $\boldsymbol{\Delta}=$ collagen-rich lesion.

$0.60 \pm 0.05$ DUR; thoracic, $0.51 \pm 0.11$ DUR; and abdominal, $0.35 \pm 0.06$ DUR), and the differences were significant in each case. Blood-pool radioactivity levels of ${ }^{99 \mathrm{~m}} \mathrm{Tc}-\mathrm{TF}-\mathrm{mAb}$ at $24 \mathrm{~h}$ were $7.5 \pm 0.0$ and $4.0 \pm 0.6 \mathrm{DUR}$ in WHHLMI and control rabbits, respectively. A/B and A/M ratios were significantly higher in WHHLMI rabbits than in control rabbits $(\mathrm{A} / \mathrm{B}, 0.38 \pm 0.09$ in WHHLMI and $0.12 \pm$ 0.02 in control rabbits; A/M, $19.3 \pm 19.1$ in WHHLMI and $1.0 \pm 0.6$ in control rabbits). In addition, the level of 99m Tc-TF-mAb accumulation in WHHLMI rabbit aortas was 1.5- to 3.3-fold higher than the level of ${ }^{99 m} \mathrm{Tc}-\mathrm{IgG}_{1}$ accumulation, and the differences were significant. 

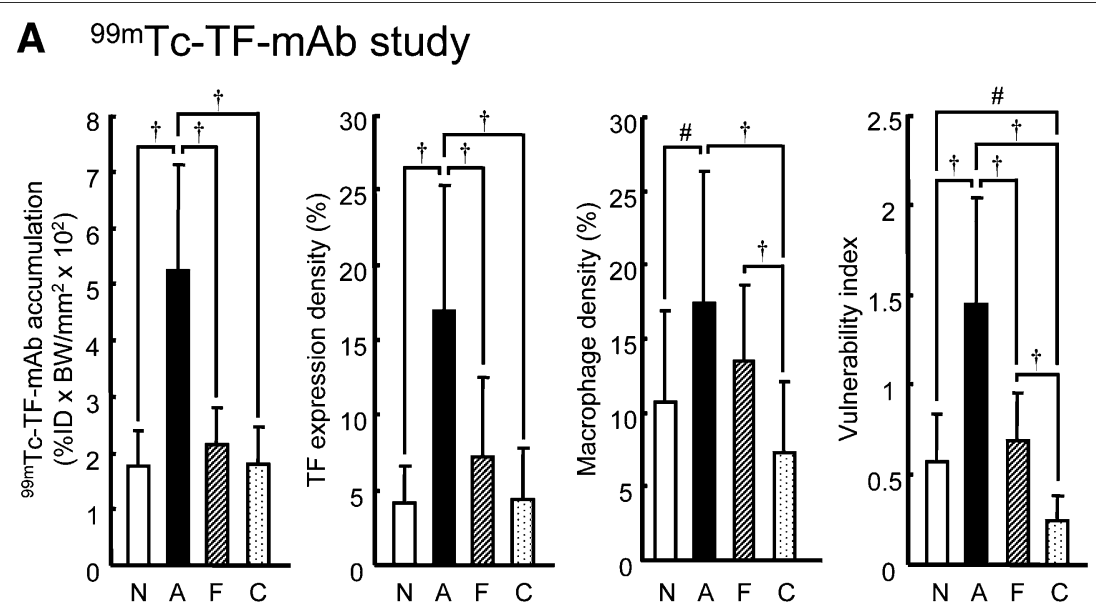

\section{B $99 m \mathrm{mc}-\mathrm{IgG}_{1}$ study}
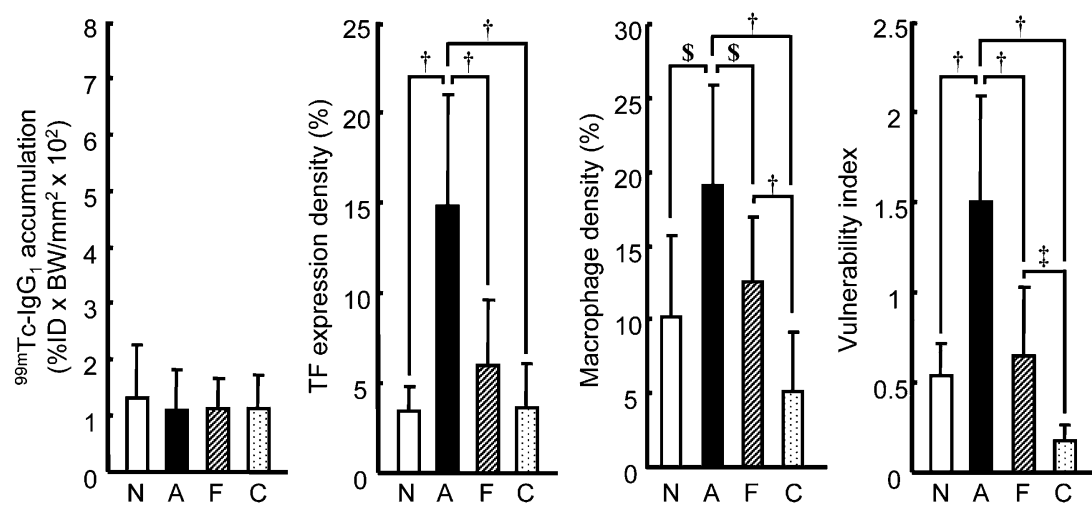

$\dagger P<0.0001, \sharp P<0.001, \mathrm{~s} P<0.01, \sharp P<0.05$

FIGURE 4. Distribution profiles of radioactivity accumulation, TF expression, macrophage density, and vulnerability index in atherosclerotic lesions in 99mTc-TF-mAb (A)

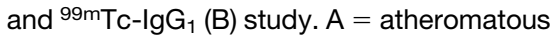
lesions; $C=$ collagen-rich lesions; $F=$ fibroatheromatous lesions; $N=$ neointimal lesions. Data are represented as mean \pm SD.

Relatively high radioactivity accumulations were found in the liver and kidneys of all 3 groups (Fig. 2). We observed that the ${ }^{99 \mathrm{~m} T c-T F-m A b}$ cleared rather more slowly from the bodies of WHHLMI rabbits than from control rabbits.

\section{Regional Distribution of ${ }^{99 \mathrm{~m} T c-T F-m A b, ~ i n ~}$ Comparison with TF Expression}

In the autoradiography study, heterogeneous ${ }^{99 \mathrm{~m}} \mathrm{Tc}-\mathrm{TF}-$ $\mathrm{mAb}$ accumulation was observed in the intima of WHHLMI rabbit aortas (Fig. 5B), whereas no marked accumulation was found in the aortas of control rabbits (Fig. 5A). Variable TF expression was detected in the intimal regions of the WHHLMI rabbit aorta (Figs. 5D, 5F, and 5G). Higher accumulation levels of ${ }^{99 \mathrm{~m} T c-T F}-\mathrm{mAb}$ were found in regions with high TF expression, whereas lower accumulation was observed in regions with low TF expression (Fig. 5 , compare $5 \mathrm{~B}$ with $5 \mathrm{~F}$ and $5 \mathrm{G}$ ). Consequently, regional ${ }^{99 \mathrm{~m}} \mathrm{Tc}-\mathrm{TF}-\mathrm{mAb}$ accumulation levels in the aorta section were positively correlated with TF expression density in WHHLMI rabbits $(R=0.64, P<0.0001)$ (Fig. 3A). No obvious TF expression was observed in the aorta of control rabbits (Figs. 5C, 5E, and 3B).

\section{Relationship Between 99mTc-TF-mAb Accumulation and Histologic Characteristics}

The plaques were categorized according to histopathologic classification criteria as follows: neointimal $(n=12$ for ${ }^{99 \mathrm{~m} T c-T F-m A b}$ study and $n=7$ for ${ }^{99} \mathrm{~m}^{\mathrm{Tc}}-\mathrm{IgG}_{1}$ study), atheromatous ( $n=40$ for ${ }^{99 \mathrm{~m} T c-T F-m A b}$ study and $n=$ 20 for ${ }^{99 \mathrm{~m} T c-I g G_{1}}$ study), fibroatheromatous ( $n=43$ for ${ }^{99 \mathrm{~m} T c-T F-m A b}$ study and $n=21$ for ${ }^{99} \mathrm{~m} \mathrm{Tc}-\mathrm{IgG}_{1}$ study), and collagen-rich $\left(n=62\right.$ for ${ }^{99 \mathrm{~m} T c-T F-m A b}$ study and $n=36$ for ${ }^{99 \mathrm{~m}} \mathrm{Tc}-\mathrm{IgG}_{1}$ study). No lesions showed hemorrhage, plaque rupture, or thrombi (type VI). The level of ${ }^{99 \mathrm{~m} T c-T F-}$ $\mathrm{mAb}$ accumulation was dependent on the histologic grade of the lesions (Fig. 4A) and was prominently and significantly the highest $(P<0.0001)$ in atheromatous lesions (type IV), compared with other lesions. The accumulation level of ${ }^{99} \mathrm{~m} \mathrm{Tc}-\mathrm{TF}-\mathrm{mAb}$ was 3.0-, 2.4-, and 2.9-fold higher in atheromatous lesions than in neointimal, fibroatheromatous, and collagen-rich lesions, respectively. The vulnerability index was also the highest in atheromatous lesions, followed in decreasing order by fibroatheromatous, neointimal, and collagen-rich lesions. Consequently, the highest level of ${ }^{99 \mathrm{~m} T c-T F-m A b}$ accumulation and the highest vulnerability 


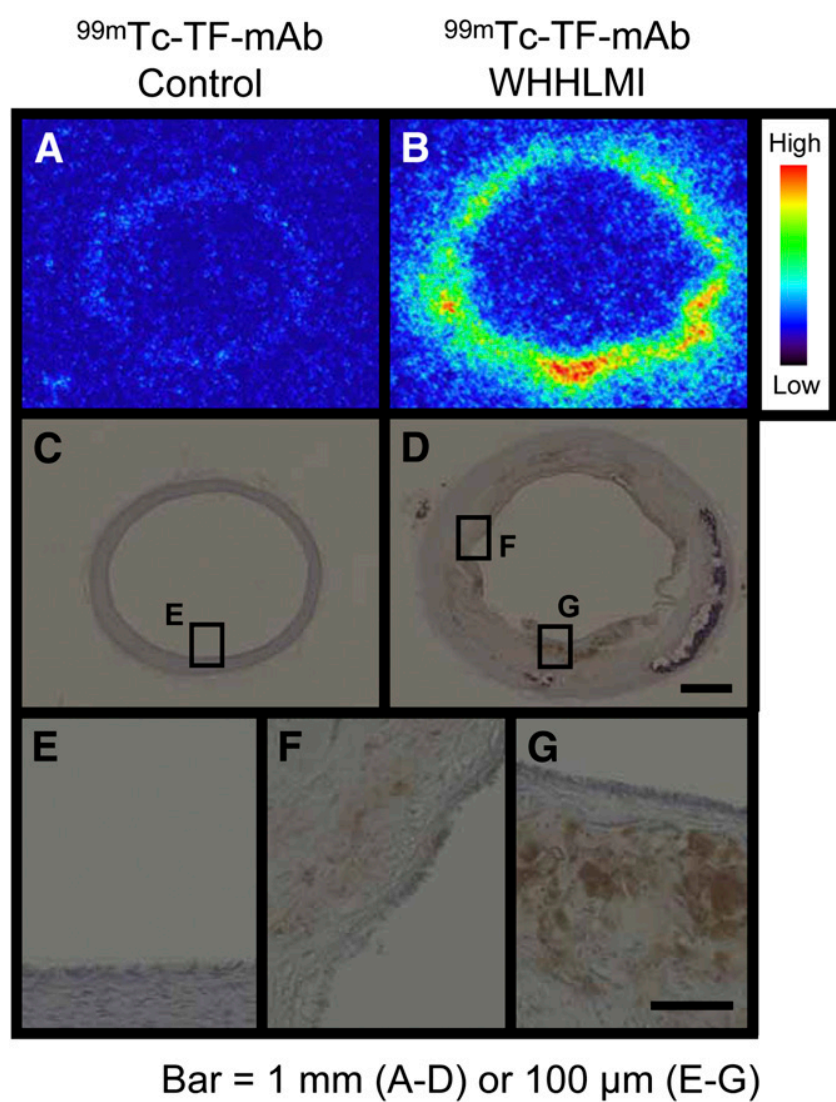

FIGURE 5. Regional distribution of ${ }^{99 \mathrm{~m} T c-T F-m A b}$ and TF expression in aortic sections. Autoradiogram ( $A$ and $B$ ) and TF immunohistochemical staining $(C-G)$ of control $(C$ and $E)$ and WHHLMI rabbits (D, F, and $G$ ). (E-G) High-magnification images of TF immunohistochemical staining in regions depicted in $C$ and $D$. Identical color window was applied to both autoradiographic images (A and $B)$. Bar $=1 \mathrm{~mm}(\mathrm{~A}-\mathrm{D})$ and $100 \mu \mathrm{m}(\mathrm{E}-\mathrm{G})$.

index were both observed in atheromatous lesions. In contrast, ${ }^{99} \mathrm{mc}-\mathrm{IgG}_{1}$ accumulation in lesions was low and did not correlate with the histologic grade of lesions, with no significant differences among the lesion types (Fig. 4B).

\section{DISCUSSION}

In the present study, we designed a new imaging agent, ${ }^{99 \mathrm{~m}} \mathrm{Tc}-\mathrm{TF}-\mathrm{mAb}$, for the purpose of discriminating atherosclerotic lesions at higher risk for rupture (thrombogenic atheromatous lesions) from more stable lesions and evaluated the potential of ${ }^{99 \mathrm{~m}} \mathrm{Tc}-\mathrm{TF}-\mathrm{mAb}$ using an atherosclerotic rabbit model. Our major findings are that a positive correlation was demonstrated between regional ${ }^{99 \mathrm{~m}} \mathrm{Tc}-\mathrm{TF}-\mathrm{mAb}$ accumulation and TF expression density in atherosclerotic lesions of WHHLMI rabbits but not with ${ }^{99 \mathrm{~m}} \mathrm{Tc}-\operatorname{IgG}_{1}$ and that significantly higher ${ }^{99 \mathrm{~m} T c-T F-m A b}$ accumulation was found in grade IV, more vulnerable atheromatous lesions, than in neointimal lesions or other more stable lesions. Thus, we demonstrate the potential of ${ }^{99 \mathrm{~m} T c-T F-m A b}$ for molecular imaging of TF expression and selectively detecting atheromatous plaques at higher risk for rupture.

\section{Immunoreactivity and Specificity of ${ }^{99 m T c-T F-m A b}$}

Immunoreactivity, specificity, and detectable but functionally silent labeling are indispensable prerequisites of in vivo molecular imaging probes using immunodetection. In this study, flow cytometric analyses indicated that modification of TF-mAb with HYNIC did not significantly affect the immunoreactivity of the original TF-mAb. In addition, autoradiography and immunohistochemical studies showed that ${ }^{99 m} \mathrm{Tc}-\mathrm{TF}-\mathrm{mAb}$ accumulation in atherosclerotic lesions correlated well with TF expression density, which was higher in atheromatous lesions, as expected (Figs. 3A and 4A). Further, contrary to the results with ${ }^{99 \mathrm{~m} T c-T F-m A b}$ (Fig. 4A), the results with ${ }^{99} \mathrm{~m} \mathrm{Tc}-\mathrm{IgG}_{1}$ (Fig. 4B) showed that accumulation of ${ }^{99 \mathrm{~m}} \mathrm{Tc}$-labeled nonspecific IgG in atheromatous lesions was not significantly different from that in other types of lesions (i.e., neointimal, fibroatheromatous, and collagen-rich lesions). These findings strongly suggest the potential of ${ }^{99 \mathrm{~m}} \mathrm{Tc}-\mathrm{TF}-\mathrm{mAb}$ to specifically recognize $\mathrm{TF}$ in vivo.

\section{TF as a Target Molecule for Plaque Imaging}

$\mathrm{TF}$, selected as a target molecule for molecular imaging in this study, initiates the exogenous blood coagulation cascade leading to thrombus formation in vivo and represents a good marker for late-stage vulnerable lesions. TF in atherosclerotic lesions was identified in several cell types, such as endothelial cells, smooth muscle cells, monocytes, macrophages, and foam cells (3), similar to lectinlike oxidized low-density lipoprotein receptor 1 (LOX-1). TF expression is reported to be increased in the later stages of atheromatous progression and thus was selectively detected in atheromatous lesions in this report (Fig. 4). These findings are comparable to those of our previous immunohistochemical study (5) and another human study (4). On these bases, TF should be a potential target for detecting atheromatous plaques at higher risk for rupture in vivo. To our knowledge, this is the first report of the development of an in vivo TF imaging probe.

On the other hand, a series of imaging agents has targeted fibrin and factor XIII in thrombi using antibodies or peptides (1), with at least partial success. In the bloodcoagulation cascade, TF initiates the system, and factor XIII covalently cross-links fibrin polymers and renders the thrombus more resistant to lysis. Therefore, ${ }^{99 \mathrm{~m} T c-}$ TF-mAb will be useful for the early detection of the cascade, and fibrin and factor XIII imaging probes can detect later stages and thrombi themselves. In this study, ${ }^{99 \mathrm{~m} T c-}$ TF-mAb corresponded with TF expression and showed preferential accumulation in atheromatous lesions and in lesions with increased vulnerability. Although further studies are required to investigate which target molecules in the cascade are most appropriate to estimate how unstable or vulnerable a plaque is in vivo, TF is a potential target. Furthermore, because great efforts have been made in the development of anticoagulation and antiplatelet pharmaceuticals for the treatment of atherosclerosis and 
hyperlipidemia, effective imaging probes to target bloodcoagulation cascades are also required for efficient drug development.

\section{Limitations of ${ }^{99 m}$ Tc-TF-mAb}

One drawback of ${ }^{99 m}$ Tc-TF-mAb is its relatively slow clearance from the blood, which is an intrinsic problem of molecular probes using antibodies. Recent advances in antibody engineering, however, should provide a promising solution for this issue. Radioprobes derived from low-molecular-weight polypeptides or compounds, small recombinant antibody fragments (Fab, scFv), engineered variants (diabodies, triabodies, minibodies, and single-domain antibodies), or pretargeting antibody methods show rapid clearance of radioactivity from the circulation (19-21). Image-subtraction techniques $(22-24)$ or kinetic model analysis $(25,26)$ may also help solve this issue. Accordingly, ${ }^{99 m}$ Tc-TF-mAb or its derivatives have great potential as in vivo molecular imaging probes and deserve further investigation.

A higher renal accumulation of ${ }^{99} \mathrm{~m}^{\mathrm{Tc}}-\mathrm{IgG}_{1}$ than of ${ }^{99} \mathrm{~m}$ Tc-TF-mAb was observed in WHHLMI rabbits. Although an exact mechanistic explanation for this significant difference is not clear, several other investigators have also reported a relatively high renal accumulation after the injection of radiolabeled mAbs (27-29). Because we evaluated the biodistribution $24 \mathrm{~h}$ after the injection (relatively late phase), renal accumulation may be ascribed to metabolic or degradation products of ${ }^{99 \mathrm{~m}} \mathrm{Tc}$-labeled antibodies (30). Thus, further ex vivo metabolite analysis studies could help to clarify the mechanism. In addition, it is known that the excretion system of WHHLMI rabbits is compromised (31), which could alter the renal accumulation of tracers. On the other hand, although a certain degree of TF expression was observed in glomeruli (32), this could not be a reason for the higher renal accumulation of ${ }^{99 m} \mathrm{Tc}-\mathrm{IgG}_{1}$.

Recently, the focus of anticoagulant research has turned to inhibition of the TF-FVIIa complex, and many pharmaceutical industry research programs have attempted to discover TF-FVIIa complex inhibitors (33). Studies in monkeys have indicated that inhibition of the TF-FVIIa complex, compared with other anticoagulants that inhibit thrombin or FXa, results in an improved profile. It is well known that the pathways for blood coagulation are interdependent, and the initiation, amplification, and propagation stages are closely regulated by positive and negative feedback loops. Thus, repeated doses of anticoagulants might increase the expression of ineffective (silent) TF complex in plaques because of such feedback processes independent of the antiatherosclerotic effect, although a lowering of net TF expression would be expected. The TF antibody we established in this study recognizes 193Ser-207Cys in the extracellular domain, which is distant from the protein sites related to complex formation with FVIIa. Therefore, the ${ }^{99 m}$ Tc-TF-mAb we developed can estimate the net TF expression in plaques, providing a useful tool to investigate the effect of such anticoagulants in vivo.

\section{Comparison with Other Imaging Probes}

In the search for suitable molecular probes to assess atherosclerotic lesion characteristics, many targets, including macrophage activity, angiogenesis, apoptosis, and cell tracking (monocyte, stem cell, lymphocyte), have been assessed (1,2,34-36). However, the usefulness of these probes is still under preliminary investigation, except for ${ }^{18} \mathrm{~F}-\mathrm{FDG}$, a marker of inflammation, and ${ }^{99 \mathrm{~m}} \mathrm{Tc}$-annexin A5, a marker of ongoing apoptotic cell death, which are currently in clinical studies. In previous studies, we evaluated macrophage imaging using ${ }^{18} \mathrm{~F}-\mathrm{FDG}$ (11) and also 99m Tc-LOX-1-mAb (17), which targets a scavenger receptor highly expressed on macrophages and foam cells and showed the usefulness for detection of atherosclerotic lesions. However, ${ }^{18}$ F-FDG accumulated in relatively stable lesions because of the presence of macrophages in such lesions, as also seen in this report (Fig. 4). We also previously showed a certain degree of LOX-1 expression in relatively stable lesions with ${ }^{99 m}$ Tc-LOX-1-mAb. As for 99m Tc-annexin A5, the accumulation ratios of atheromatous lesions to other lesions of ${ }^{99 \mathrm{~m}} \mathrm{Tc}-\mathrm{TF}-\mathrm{mAb}$ (atheromatous to neointimal, 3.0; atheromatous to fibroatheromatous, 2.4; and atheromatous to collagen-rich, 2.9) were markedly higher than those of ${ }^{99 \mathrm{~m}} \mathrm{Tc}$-annexin A5 (atheromatous to neointimal,1.3; atheromatous to fibroatheromatous, 1.3; atheromatous to collagen-rich, 1.8) (15). Our previous study in apolipoprotein E-null mice also showed relatively high ${ }^{18}$ F-FDG accumulation levels in early lesions, resulting in lower accumulation ratios for advanced to early lesions in comparison with ${ }^{99 \mathrm{~m}} \mathrm{Tc}$-annexin A5 (37). Thus, the desirable features of ${ }^{99 \mathrm{~m}} \mathrm{Tc}-\mathrm{TF}-\mathrm{mAb}$ further confirm its potential as a molecular probe for detecting atheromatous lesions at higher risk for rupture.

\section{CONCLUSION}

In this study, we succeeded in determining TF expression using ${ }^{99 \mathrm{~m}} \mathrm{Tc}-\mathrm{TF}-\mathrm{mAb}$ in WHHLMI rabbits. Consequently, we demonstrated prominently higher accumulation of $99 \mathrm{~m} \mathrm{Tc}-$ TF-mAb in grade IV atheroma. These findings strongly indicate that molecular imaging of TF should provide clinically useful information on the thrombogenicity of atherosclerotic plaques.

\section{ACKNOWLEDGMENTS}

This work was partly supported by a grant-in-aid for general scientific research from the Ministry of Education, Culture, Sports, Science and Technology of Japan and from the Japan Society for the Promotion of Science and by a research grant from the Association for Nuclear Technology in Medicine and Takeda Science Foundation.

\section{REFERENCES}

1. Shaw SY. Molecular imaging in cardiovascular disease: targets and opportunities. Nat Rev Cardiol. 2009;6:569-579.

2. Saraste A, Nekolla SG, Schwaiger M. Cardiovascular molecular imaging: an overview. Cardiovasc Res. 2009;83:643-652. 
3. Moons AH, Levi M, Peters RJ. Tissue factor and coronary artery disease. Cardiovasc Res. 2002;53:313-325.

4. Jeanpierre E, Le Tourneau T, Six I, et al. Dietary lipid lowering modifies plaque phenotype in rabbit atheroma after angioplasty: a potential role of tissue factor. Circulation. 2003;108:1740-1745.

5. Kuge Y, Kume N, Ishino S, et al. Prominent lectin-like oxidized low density lipoprotein (LDL) receptor-1 (LOX-1) expression in atherosclerotic lesions is associated with tissue factor expression and apoptosis in hypercholesterolemic rabbits. Biol Pharm Bull. 2008;31:1475-1482.

6. Shiomi M, Ito T, Yamada S, Kawashima S, Fan J. Development of an animal model for spontaneous myocardial infarction (WHHLMI rabbit). Arterioscler Thromb Vasc Biol. 2003;23:1239-1244.

7. Abrams MJ, Juweid M, tenKate CI, et al. Technetium-99m-human polyclonal IgG radiolabeled via the hydrazino nicotinamide derivative for imaging focal sites of infection in rats. J Nucl Med. 1990;31:2022-2028.

8. Ono M, Arano Y, Mukai T, et al. Plasma protein binding of ${ }^{99 \mathrm{~m}} \mathrm{Tc}$-labeled hydrazino nicotinamide derivatized polypeptides and peptides. Nucl Med Biol. 2001;28:155-164.

9. Larsen SK, Solomon HF, Caldwell G, Abrams MJ. [ $\left.{ }^{99 \mathrm{~m}} \mathrm{Tc}\right]$ tricine: a useful precursor complex for the radiolabeling of hydrazinonicotinate protein conjugates. Bioconjug Chem. 1995;6:635-638.

10. Ishii K, Kita T, Kume N, Nagano Y, Kawai C. Uptake of acetylated LDL by peritoneal macrophages obtained from normal and Watanabe heritable hyperlipidemic rabbits, an animal model for familial hypercholesterolemia. Biochim Biophys Acta. 1988;962:387-389.

11. Ogawa M, Ishino S, Mukai T, et al. ${ }^{18} \mathrm{~F}-\mathrm{FDG}$ accumulation in atherosclerotic plaques: immunohistochemical and PET imaging study. J Nucl Med. 2004;45:12451250 .

12. Stary HC, Chandler AB, Glagov S, et al. A definition of initial, fatty streak, and intermediate lesions of atherosclerosis: a report from the Committee on Vascular Lesions of the Council on Arteriosclerosis, American Heart Association. Circulation. 1994;89:2462-2478.

13. Stary HC, Chandler AB, Dinsmore RE, et al. A definition of advanced types of atherosclerotic lesions and a histological classification of atherosclerosis: a report from the Committee on Vascular Lesions of the Council on Arteriosclerosis, American Heart Association. Circulation. 1995;92:1355-1374.

14. Kobayashi S, Inoue N, Ohashi Y, et al. Interaction of oxidative stress and inflammatory response in coronary plaque instability: important role of C-reactive protein. Arterioscler Thromb Vasc Biol. 2003;23:1398-1404.

15. Ishino $\mathrm{S}$, Kuge $\mathrm{Y}$, Takai $\mathrm{N}$, et al. ${ }^{99 \mathrm{~m}} \mathrm{Tc}-$ Annexin A5 for noninvasive characterization of atherosclerotic lesions: imaging and histological studies in myocardial infarction-prone Watanabe heritable hyperlipidemic rabbits. Eur J Nucl Med Mol Imaging. 2007;34:889-899.

16. Shiomi M, Ito T, Hirouchi Y, Enomoto M. Stability of atheromatous plaque affected by lesional composition: study of WHHL rabbits treated with statins. Ann N Y Acad Sci. 2001;947:419-423.

17. Ishino S, Mukai T, Kuge Y, et al. Targeting of lectinlike oxidized low-density lipoprotein receptor 1 (LOX-1) with ${ }^{99 \mathrm{~m}} \mathrm{Tc}$-labeled anti-LOX-1 antibody: potential agent for imaging of vulnerable plaque. J Nucl Med. 2008;49:1677-1685.

18. Shiomi M, Ito T, Hirouchi Y, Enomoto M. Fibromuscular cap composition is important for the stability of established atherosclerotic plaques in mature WHHL rabbits treated with statins. Atherosclerosis. 2001;157:75-84.
19. Huhalov A, Chester KA. Engineered single chain antibody fragments for radioimmunotherapy. Q J Nucl Med Mol Imaging. 2004;48:279-288.

20. Sharkey RM, Karacay H, Cardillo TM, et al. Improving the delivery of radionuclides for imaging and therapy of cancer using pretargeting methods. Clin Cancer Res. 2005;11:7109s-7121s.

21. Sano K, Temma T, Kuge Y, et al. Radioimmunodetection of membrane type-1 matrix metalloproteinase relevant to tumor malignancy with a pre-targeting method. Biol Pharm Bull. 2010;33:1589-1595.

22. Temma T, Iida H, Hayashi $\mathrm{T}$, et al. Quantification of regional myocardial oxygen metabolism in normal pigs using positron emission tomography with injectable ${ }^{15} \mathrm{O}-\mathrm{O}_{2}$. Eur J Nucl Med Mol Imaging. 2010:37:377-385.

23. Yamamoto $\mathrm{Y}$, de Silva R, Rhodes CG, et al. Noninvasive quantification of regional myocardial metabolic rate of oxygen by ${ }^{15} \mathrm{O}_{2}$ inhalation and positron emission tomography: experimental validation. Circulation. 1996;94:808-816.

24. Iida H, Rhodes CG, Araujo LI, et al. Noninvasive quantification of regional myocardial metabolic rate for oxygen by use of ${ }^{15} \mathrm{O}_{2}$ inhalation and positron emission tomography: theory, error analysis, and application in humans. Circulation. 1996;94:792-807.

25. Watabe H, Ikoma Y, Kimura Y, Naganawa M, Shidahara M. PET kinetic analysis: compartmental model. Ann Nucl Med. 2006;20:583-588.

26. Ikoma Y, Watabe H, Shidahara M, Naganawa M, Kimura Y. PET kinetic analysis: error consideration of quantitative analysis in dynamic studies. Ann Nucl Med. 2008;22:1-11.

27. Rogers BE, Anderson CJ, Connett JM, et al. Comparison of four bifunctional chelates for radiolabeling monoclonal antibodies with copper radioisotopes: biodistribution and metabolism. Bioconjug Chem. 1996;7:511-522.

28. Sugimoto K, Nishimoto N, Kishimoto T, Yoshizaki K, Nishimura T. Imaging of lesions in a murine rheumatoid arthritis model with a humanized anti-interleukin-6 receptor antibody. Ann Nucl Med. 2005;19:261-266.

29. D'Alessandria C, Malviya G, Viscido A, et al. Use of a ${ }^{99 m} \mathrm{Tc}$ labeled anti-TNF $\alpha$ monoclonal antibody in Crohn's disease: in vitro and in vivo studies. $Q \mathrm{~J} \mathrm{Nucl}$ Med Mol Imaging. 2007;51:334-342.

30. Akizawa H, Arano Y. Altering pharmacokinetics of radiolabeled antibodies by the interposition of metabolizable linkages: metabolizable linkers and pharmacokinetics of monoclonal antibodies. Q J Nucl Med. 2002;46:206-223.

31. Campean V, Neureiter D, Varga I, et al. Atherosclerosis and vascular calcification in chronic renal failure. Kidney Blood Press Res. 2005;28:280-289.

32. Drake TA, Morrissey JH, Edgington TS. Selective cellular expression of tissue factor in human tissues: implications for disorders of hemostasis and thrombosis. Am J Pathol. 1989;134:1087-1097.

33. Prezelj A, Anderluh PS, Peternel L, Urleb U. Recent advances in serine protease inhibitors as anticoagulant agents. Curr Pharm Des. 2007;13:287-312.

34. Davies JR, Rudd JH, Weissberg PL, Narula J. Radionuclide imaging for the detection of inflammation in vulnerable plaques. J Am Coll Cardiol. 2006;47(8, suppl):C57-C68.

35. Jaffer FA, Libby $P$, Weissleder R. Molecular and cellular imaging of atherosclerosis: emerging applications. J Am Coll Cardiol. 2006;47:1328-1338.

36. Rudd JH, Hyafil F, Fayad ZA. Inflammation imaging in atherosclerosis. Arterioscler Thromb Vasc Biol. 2009;29:1009-1016.

37. Zhao Y, Kuge Y, Zhao S, et al. Comparison of ${ }^{99 \mathrm{~m}} \mathrm{Tc}$-annexin A5 with ${ }^{18} \mathrm{~F}-\mathrm{FDG}$ for the detection of atherosclerosis in ApoE-/- mice. Eur J Nucl Med Mol Imaging. 2007;34:1747-1755.

\section{Erratum}

In the article " ${ }^{18}$ F-FDG PET After 2 Cycles of ABVD Predicts Event-Free Survival in Early and Advanced Hodgkin Lymphoma," by Cerci et al. (J Nucl Med. 2010;51:1337-1343), Figure 4 contained a mistake. The graph of eventfree survival in patients with a low International Prognostic Score should indicate that 10 of 18 patients (not 3 of 30) were PET2-positive. The authors regret the error. 